\title{
Eksplorasi Minat Belajar Matematika Melalui Diary Siswa di Sekolah Dasar
}

\author{
Nelly Rhosyida, Mahmudah Titi Muanifah, Trisniawati
}

Universitas Sarjanawiyata Tamansiswa

rhosyidanelly@gmail.com

\section{Sejarah Artikel}

diterima 07/10/2019

\begin{abstract}
The purpose of this research is to describe students 'interest in learning mathematically through the diary of students in elementary school and describe the factors that affect students' interest in learning mathematics in elementary school. This research was conducted in class IV SD Ngebelgede 1 Sleman Yogyakarta. There are 22 students in class IV. This type of research uses qualitative research with case study methods. The instruments used were student diary books and character emoticons. Data analysis is carried out through stages, namely data reduction, data presentation, drawing conclusions and verification as well as checking the validity of the data with triangulation techniques. The results of this study can be seen from the diary of students that students are happy with learning mathematics, even enthusiastic when they get good grades even during midterm assessments, but there are also students who are sad when math grades are low.
\end{abstract}

Keywords: interest in learning, student's diary, primary school.

\begin{abstract}
Abstrak
Tujuan penelitian adalah mendeskripsikan minat belajar matematis siswa melalui diary siswa di sekolah dasar dan mendeskripsikan faktor-faktor yang mempengaruhi minat belajar matematika siswa di sekolah dasar. Penelitian ini dilaksanakan di kelas IV SD Ngebelgede 1 Sleman Yogyakarta. Banyaknya siswa kelas IV ada 22 siswa. Jenis penelitian ini menggunakan penelelitian kualitatif dengan metode studi kasus. Instrumen yang digunakan adalah buku diary siswa dan emoticon karakter. Analisis data dilakukan melalui tahap-tahap yaitu reduksi data, penyajian data, penarikan simpulan dan verifikasi serta pengecekan keabsahan data dengan teknik triangulasi. Hasil dari penelitian ini yaitu dapat diketahui dari diary siswa bahwa siswa senang terhadap pembelajaran matematika, bahkan antusias ketika mendapat nilai baik bahkan saat penilaian tengah semester, namun ada juga siswa yang sedih ketika nilai matematika jelek. Kata kunci: minat belajar, diary siswa, sekolah dasar.
\end{abstract}




\section{PENDAHULUAN}

Pembelajaran matematika yang diajarkan di sekolah dasar dan menengah tentu mempunyai tujuan yang ingin dicapai. Tujuan pembelajaran matematika di sekolah bukan hanya membentuk siswa terampil dalam menggunakan matematika, tetapi juga terampil pada aspek kognitif, afektif dan psikomotor. Menurut Mayer (2003), "learning is the construction of knowledge; memory is the storage of knowledge; and thinking is the logical manipulation of knowledge". Artinya belajar adalah konstruksi pengetahuan, penyimpanan memori pengetahuan, dan berpikir dengan manipulasi logis terhadap pengetahuan.

Sejalan dengan Smaldino, et al (2008) mendefinisikan belajar sebagai berikut: "learning is the development of knowledges, skills, or attitudes as an individual interacts with information and the environment. The learning environment is orchestrated by the teacher and includes the physical facilities, the academic and emotional atmosphere, and instructional technology." Artinya, belajar adalah pengembangan pengetahuan, keterampilan, atau sikap karena interaksi seorang individu dengan informasi dan lingkungan. Lingkungan pembelajaran diatur oleh guru dan meliputi fasilitas fisik, atmosfir akademik dan emosional, serta teknologi pengajaran.

Berdasarkan peraturan menteri pendidikan nasional nomor 22 tahun 2006 tentang standar isi, pembelajaran matematika tingkat SD/MI memiliki tujuan agar peserta didik memiliki kemampuan berikut ini.

1. Memahami konsep matematika, menjelaskan keterkaitan antarkonsep dan mengaplikasikan konsep atau algoritma, secara luwes, akurat, efisien, dan tepat, dalam pemecahan masalah.

2. Menggunakan penalaran pada pola dan sifat, melakukan manipulasi matematika dalam membuat generalisasi, menyusun bukti, atau menjelaskan gagasan dan pernyataan matematika.

3. Memecahkan masalah yang meliputi kemampuan memahami masalah, merancang model matematika, menyelesaikan model dan menafsirkan solusi yang diperoleh.

4. Mengomunikasikan gagasan dengan simbol, tabel, diagram, atau media lain untuk memperjelas keadaan atau masalah.

5. Memiliki sikap menghargai kegunaan matematika dalam kehidupan, yaitu memiliki rasa ingin tahu, perhatian, dan minat dalam mempelajari matematika, serta sikap ulet dan percaya diri dalam pemecahan masalah.

Berdasarkan tujuan umum di atas, pembelajaran matematika pada jenjang pendidikan sekolah dasar memberi tekanan pada pemahaman konsep, penalaran, kemampuan pemecahan masalah, mengkomunikasikan ide-ide serta sikap menghargai matematika. Tujuan yang paling tinggi tingkatannya adalah sikap menghargai siswa dalam matematika. Hal ini salah satunya bisa ditunjukkan dengan mengetahui minat siswa terhadap pembelajaran matematika.

Minat merupakan suatu perasaan atas pilihan terhadap kegiatan, cita-cita, atau objek tertentu (Aiken, 1999: 259). Minat memiliki karateristik pokok, yaitu melakukan 
suatu kegiatan yang dipilih sendiri dan menyenangkan sehingga dapat membentuk suatu kebiasaan dalam diri seseorang. Minat dalam pembelajaran matematika dapat diartikan sebagai kesenangan dan ketertarikan untuk memahami matematika lebih dalam dan kebiasaan untuk belajar matematika.

Minat merupakan pilihan bentukbentuk tertentu dari suatu aktivitas ketika seseorang tidak sedang berada dalam tekanan dari luar dirinya (Nitko, 2007: 448). Menurut Elliot, et al (2000: 349) minat berhubungan dengan keingintahuan, minat merupakan suatu sifat abadi yang ditunjukkan dengan suatu hubungan antara seseorang dengan aktivitas atau objek tertentu. Sax (1980: 473) menyatakan bahwa minat merupakan pilihan terhadap satu kegiatan dibandingkan dengan yang lainnya. Pengertian ini menekankan pada dua hal. Pertama, minat melibatkan pilihan dan rangking dari kegiatan sepanjang dimensi sukatidak suka. Kedua, minat melibatkan aktifitas atau perilaku yang digunakan oleh individu. Lebih lanjut dalam Trisniawati (2019) mengemukakan "a person's interest in learning does not arise by itself. There are several factors that can influence a person's learning interest, especially when someone is learning mathematics. Not infrequently people are afraid to learn mathematics".

Menurut Strong, dalam Savickas \& Spokane (1999: 22-23), dalam pandangan kualitatif terdapat empat unsur minat. Dua unsur kualitatif yang pertama adalah ketekunan memperhatikan, dan suatu perasaan suka terhadap objek. Selanjutnya Strong mengungkapkan unsur kualitatif yang ketiga adalah tujuan karena kegemaran mengarahkan seseorang terhadap objek dan ketidaksukaan mengarahkan seseorang untuk menjauhi suatu objek. Unsur yang keempat dari minat adalah aktivitas, seseorang yang berminat melakukan sesuatu yang berhubungan dengan objek. Selain unsur kualitatif, Strong juga mengungkapkan dua unsur dalam pandangan kuantitatif yaitu intensitas dan durasi. Intensitas berhubungan dengan kecenderungan terhadap sesuatu daripada yang lain, dan durasi berhubungan dengan jangka waktu suatu perilaku berlangsung.

Sementara itu, Ainley, et al (2002) mengemukakan bahwa secara umum minat individu dalam pembelajaran diekspresikan melalui keinginan memperoleh informasi yang baru, mengetahui tentang seuatu objek, peristiwa, dan ide baru tanpa dibatasi bidang yang sempit. Deci (Elliot et al, 2000: 349) menyatakan bahwa "interest occurs when a student's needs, capacities, and skill are good match the demands offered by a particular activity". Artinya, minat muncul ketika kebutuhan, kemampuan, dan keterampilan peserta didik sangat sesuai dengan kebutuhan yang ditawarkan oleh aktivitas tertentu.

Sementara itu Stipek (Woolfolk, 2007: 384) berpendapat bahwa "interest increase when students feel competent, so even if student are not initially interested in a subject or activity, they may develop interests as they experience success." Artinya, minat akan meningkat ketika siswa merasa mampu, bahkan jika siswa pada awalnya tidak tertarik pada suatu subjek atau aktifitas, mereka mungkin mengembangkan minat saat mereka memperoleh pengalaman sukses.

Sebagai mata pelajaran yang menuntut siswa dalam memahami konsep dan memecahkan 
permasalahan matematika yang cenderung menggunakan rumus, matematika masih sering dianggap siswa mata pelajaran yang sulit dan tidak jarang siswa tidak tertarik mengikuti pembelajaran matematika di kelas bahkan menghindari mata pelajaran ini.

Dalam bidang studi matematika, minat seseorang terhadap pelajaran dapat dilihat dari kecenderungan untuk memberikan perhatian yang lebih besar terhadap pelajaran tersebut.Bila seseorang mempunyai minat yang besar terhadap pelajaran matematika maka nilai hasil belajarnya cenderung berubah ke arah yang lebih baik. Sedangkan menenurut Djamarah (2002: 157) menyebutkan "Minat belajar cenderung menghasilkan prestasi yang tinggi, sebaliknya minat belajar yang kurang akan menghasilkan prestasi belajar yang rendah". Minat yang besar terhadap sesuatu merupakan modal yang besar artinya untuk mencapai atau memperoleh benda atau tujuan yang diminati itu. Dalam mengetahui minat belajar siswa, salah satu hal yang dapat dilakukan yaitu dengan memberikan diary siswa.

Diary book atau buku harian merupakan buku khusus untuk mengungkapkan pengalaman yang menyenangkan, pengalaman yang menyedihkan, menjengkelkan, rasa puas, rasa kecewa, dan pemikiran yang muncul pada hari itu (Asul, dkk, 2005: 2). Diary tidak serta merta harus berisi tulisan, tetapi juga bisa berisi gambar. Hal ini tentu saja dikarenakan ada beberapa orang yang tidak dapat menuliskan secara langsung apa yang dia rasakan saat itu.

Diary dapat digunakan sebagai media untuk menuliskan cerita atau kejadian yang terjadi pada siswa yang mereka anggap penting. "Diary is book used for daily record of events, future appointments, etc" (Oxford University Press, 2008: 123). Artinya diary adalah sebuah buku yang digunakan untuk menuliskan kejadian sehari-hari, agenda kegiatan yang akan dilaksanakan, dan sebagainya. Diary ini dapat membantu guru untuk mengidentifikasi faktor-faktor yang dapat meningkatkan atau menghambat proses pembelajaran matematika khususnya minat siswa terhadap mata pelajaran matematika. Sependapat dengan Scrivener (2005) yaitu "This media is chosen because writing a diary is a simple activity that could provoke students to express ideas and feelings in their daily activities. Writing a diary could be new ways for students conducts writing activity everyday. Beyond these new ways of communicating, many people actually do very little writing in day-today life such as diary entries."

Penulisan diary ini hendaknya dilakukan dengan rutin setiap selesai pembelajaran. Kemudian dari hasil diary yang ditulis siswa ini, guru dapat mengetahui kesan terhadap pembelajaran dan apa saja yang dirasakan siswa terhadap pembelajaran yang sudah diikuti. Oleh karena itu penting dan sangat bermanfaat dilakukannya analysis terhadapt hasil tulisan dalam diary siswa untuk dapat mengetahui minat terhadap pembelajaran khususnya pembelajaran matematika.

Berdasarkan permasalahan diatas maka tujuan penelitian adalah mendeskripsikan minat belajar matematis siswa melalui diary siswa di sekolah dasar dan mendeskripsikan faktor-faktor yang mempengaruhi minat belajar matematika siswa di sekolah dasar. 


\section{METODE}

Penelitian ini menggunakan pendekatan kualitatif Meleong (2005). Penelitian ini diharapkan agar dapat mengungkap secara lebih cermat mengenai minat belajar matematika melalui diary siswa di sekolah dasar. Peneliti memilih jenis penelitian studi kasus. Tujuan pemilihan jenis penelitian tersebut adalah untuk mengetahui secara langsung dan lebih rinci mengenai minat belajar matematika melalui diary siswa di sekolah dasar.

Subjek penelitiannya adalah siswa kelas IV SD N Ngebelgede 1 Sleman Yogyakarta. Banyaknya siswa kelas IV ada 22 siswa. Instrumen yang digunakan adalah buku diary siswa dan emoticon karakter.

Analisis data dilakukan melalui tahap-tahap yaitu reduksi data, penyajian data, penarikan simpulan dan verifikasi serta pengecekan keabsahan data dengan teknik triangulasi. Menurut Sugiyono (2013:
330) teknik triangulasi berarti peneliti menggunakan teknik pengumpulan data yang berbeda-beda untuk mendapatkan data dari sumber data yang sama. Peneliti menggunakan observasi partisipatif, wawancara mendalam, Serta dokumentasi untuk sumber data yang sama secara serempak. Teknik triangulasi lebih mengutamakan efektivitas proses dan hasil yang diinginkan. Triangulasi dapat dilakukan dengan menguji apakah proses dan hasil metode yang digunakan sudah berjalan dengan baik.

Hasil diary siswa yang telah diperoleh perlu diuji lagi dengan informan-informan sebelumnya. Apabila terdapat perbedaan, peneliti harus menelusuri perbedaan tersebut sampai peneliti memperoleh sumber perbedaan dan materi perbedaannya, kemudian dilakukan konfirmasi dengan informan dan sumber-sumber lainnya.

\section{PEMBAHASAN}

Kegiatan pembelajaran yang dilaksanakan setiap hari dengan jadwal yang berbeda tentu akan memberikan kesan yang berbedabeda pada setiap siswa. Dalam hal ini perlu diketahui kesan atau perasaan siswa setelah mengikuti pembelajaran setiap harinya yaitu dengan diary siswa. Pengisian diary siswa dilaksanakan setiap hari dan diisi siswa dirumah setelah pulang sekolah.

Kegiatan pertama yang dilakukan adalah pemberian diary siswa dan stiker emoticon karakter, serta bolpoin dengan berbagai warna. Stiker emoticon terdiri dari stiker karakter, kemudian stiker matematika dan stiker gambar penanaman karakter seperti sopan, salam, disiplin, dll. Kemudian guru memberikan petunjuk bagaimana cara menulis diary siswa, yaitu siswa menulis sesuai dengan kesan yang dirasakan setelah pembelajaran secara bebas, kemudian siswa dapat menempelkan stiker yang telah diberikan secara bebas, dan dapat menulis dengan bolpoin warna warni sesuai dengan kesukaan siswa. Penulisan diary siswa ini berlangsung selama 3 minggu kemudian hasilnya dianalisis oleh peneliti.

Berikut ini adalah hasil tulisan pada diary siswa kelas IV SD Ngebelgede 1 Sleman Yogyakarta: 


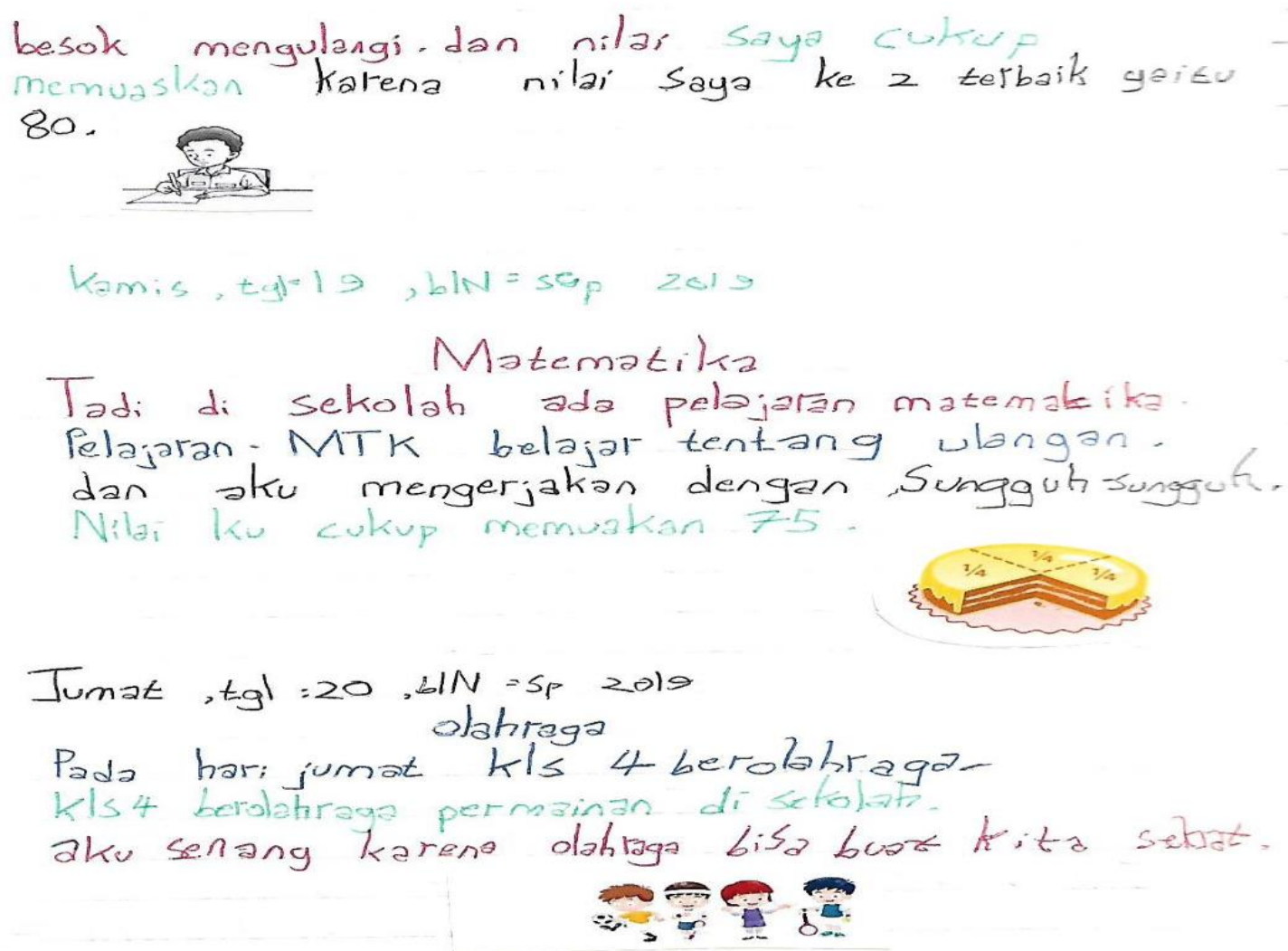

\section{Gambar 1. Diary Siswa Da}

Berdasarkan tulisan tersebut Siswa Da menuliskan pada diary nya yaitu ketika ulangan dan belajar sungguh-sungguh agar lulus dari KKM. Hal ini menunjukkan bahwa siswa Da mempunyai minat belajar matematika yang tinggi karena dengan bersungguh-sungguh belajar matematika. Lebih lanjut saat wawancara dengan guru diperoleh keterangan bahwa siswa Da. memang aktif dalam diskusi kelompok, aktif ketika mengerjakan soal dan menulis di papan tulis serta nilainya ketika penilaian harian diatas KKM.

Kemudian berikut ini pengisian diary siswa Di. : 


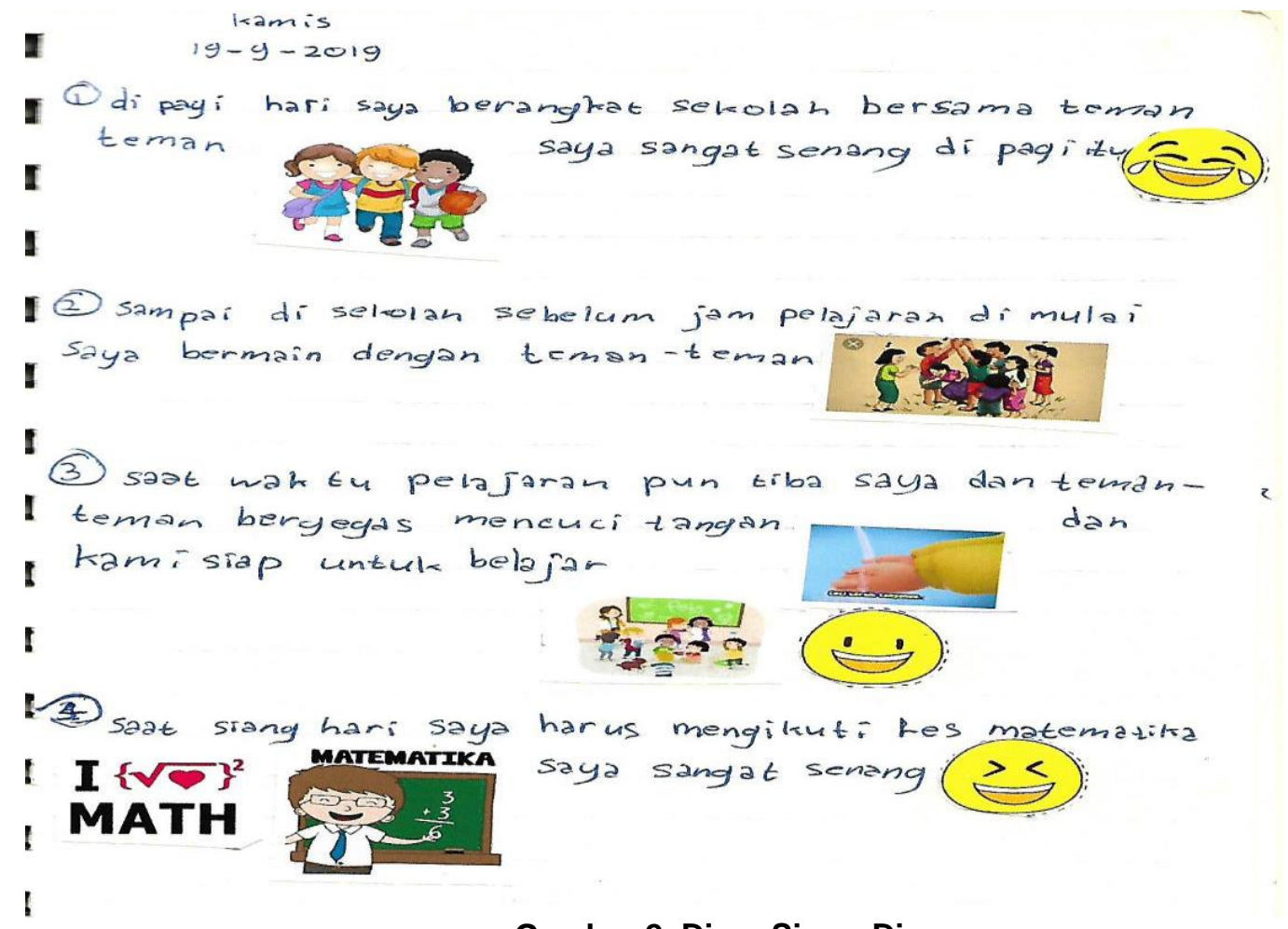

Gambar 2. Diary Siswa Di.

Berdasarkan tulisan tersebut Siswa Di. menuliskan pada diary nya yaitu belajar dan les matematika maka dia senang dan bersemangat. Hal ini dibuktikan dengan menempelkan stikel "ilovemath" dan stiker "senyum" pada diary siswa tersebut. Hal ini menunjukkan bahwa siswa Di. mempunyai minat belajar matematika yang tinggi karena dengan senang ketika belajar dan les matematika. Selain itu minat belajar ditunjukkan dengan melakukan persiapan seperti belajar materi sebelumnya dan senang ketika pembelajaran

matematika berlangsung. Lebih lanjut saat wawancara dengan guru diperoleh keterangan bahwa siswa Di. memang aktif ketika ditanya oleh guru dan sering maju mengerjakan soal ketika pembelajaran. Namun ketika dalam diskusi kelompok, siswa Di. cenderung mengerjakan tugas sendiri dan tidak mau berbagi tugas dengan teman sekelompoknya sehingga dalam keterampilan social dalam berdiskusi masih kurang.

Berikut ini pengisian diary siswa Ha. : 


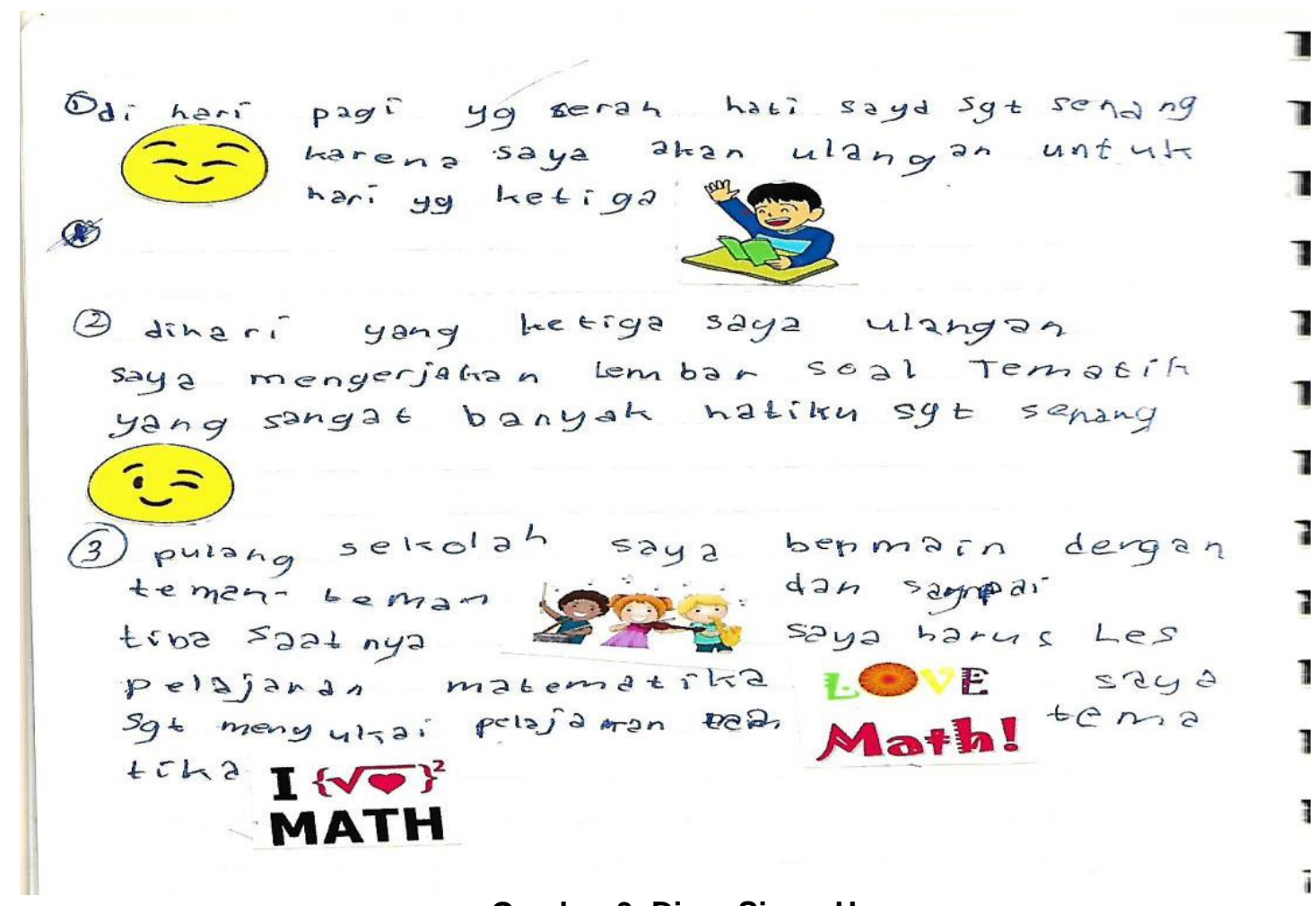

Gambar 3. Diary Siswa Ha

Berdasarkan tulisan tersebut Siswa $\mathrm{Ha}$. menuliskan pada diary nya yaitu setelah bermain bersama-sama dengan teman-teman kemudian mengikuti les matematika dengan senang dan gembira. Hal ini dibuktikan dengan menempelkan stikel "ilovemath" dan stiker "lovemath" pada diary siswa tersebut. Hal ini menunjukkan bahwa siswa $\mathrm{Ha}$. mempunyai minat belajar matematika yang tinggi karena dengan senang ketika belajar dan les matematika.

Berdasarkan

wawancara dengan guru diperoleh informasi bahwa siswa Ha. aktif dalam kegiatan diskusi kelompok dan ketika mengerjakan soal matematika dapat menjawab dengan benar, hanya ketika diminta maju ke depan siswa $\mathrm{Ha}$. kadang masih belum mau mengerjakan didepan, seringkali guru harus menyuruh berkali-kali baru siswa Ha. mau untuk mengerjakan ke depan kelas

Selain minat terhadap pembelajaran matematika dapat pula diketahui mengenai aktivitas yang dilakukan oleh siswa baik kegiatan di pagi hari sebelum sekolah, kegiatan siang dan sore hari setelah pulang sekolah, dan kegiatan di malam hari seperti berikut ini: 


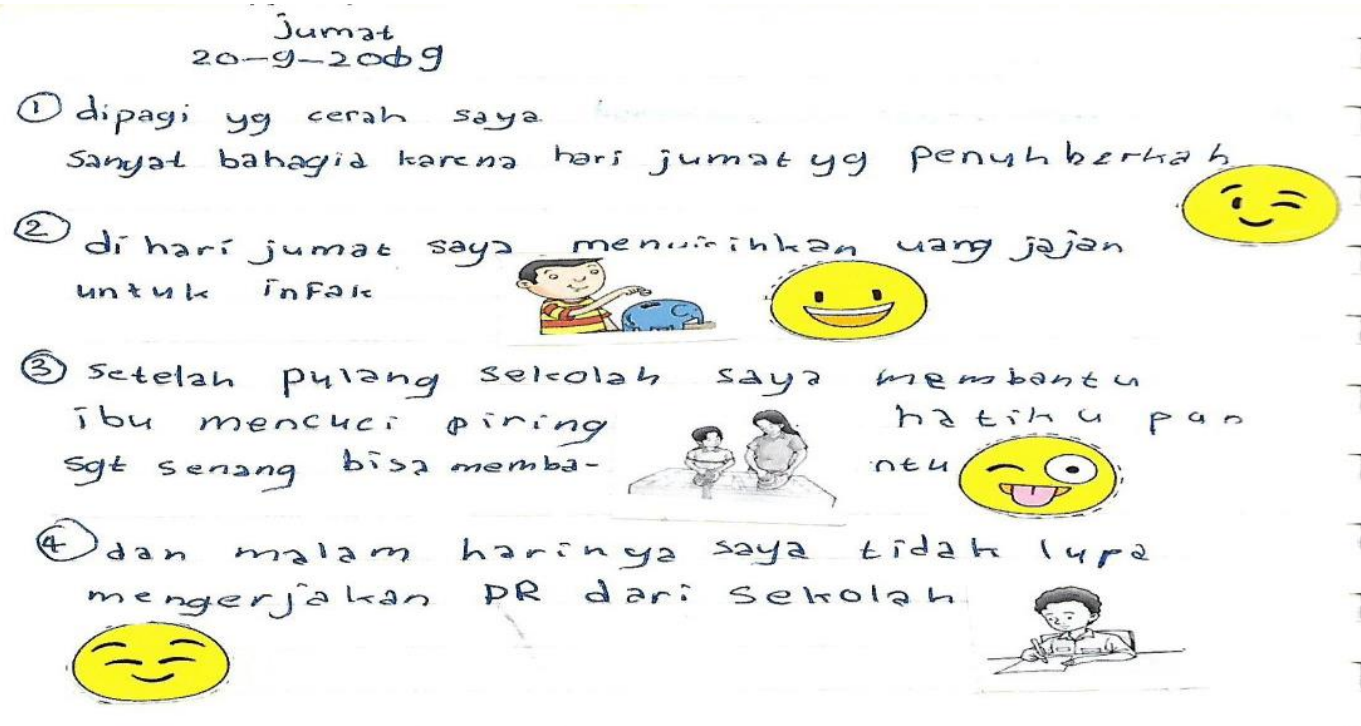

Gambar 4. Diary Aktivitas Siswa Di

Berdasarkan tulisan tersebut Siswa Di. menuliskan pada diary nya yaitu kegiatan dipagi hari yaitu pada hari Jumat siswa menyisihkan sebagian uang jajan untuk infaq, kemudian kegiatan disore hari membantu ibu mencuci piring dan menyiram tanaman bersama ibu, kemudian kegiatan malam hari mengerjakan PR yang telah diberikan guru. Hal ini menunjukkan bahwa siswa Di. adalah siswa yang rajin, membantu ibu, dan disiplin dalam mengerjakan tugas yang diberikan oleh guru, kemudian siswa juga senang dalam melaksanakan kegiatan yang ada ditunjukkan dengan menempel stiker emoticon "senyum".

Berdasarkan beberapa contoh diary dan wawancara yang dilakukan oleh guru, maka dapat terlihat siswa kelas IV SD Ngebelgede Sleman Yogyakarta mempunyai minat yang tinggi terhadap pembelajaran matematika dan pemberian diary siswa, stiker emoticon karakter, dan bolpoin warna dapat menjadi sarana siswa untuk mengungkapkan kesan dan perasaan terhadap pembelajaran. Selain itu pemberian diary siswa juga dapat mengetahui minat belajar terhadap pembelajaran matematika.

$\mathrm{Hal}$ ini sesuai dengan Hasil penelitian tindakan kelas tentang peningkatan minat belajar matematika, yang dilakukan oleh Fricke (2007) menyimpulkan bahwa diskusi dan pemberian catatan harian siswa merupakan hal yang penting dan efektif. Data menunjukkan bahwa siswa mengapresiasi pemberian catatan harian siswa dan dapat meningkatkan minat belajar siswa.

Berdasarkan hasil wawancara dengan siswa terdapat beberapa faktor pendukung minat belajar siswa diantaranya siswa senang ketika pembelajaran matematika karena menggunakan media pembelajaran yang bervariatif yaitu ada video dan ada media konkret seperti kubus satuan, uang mainan, dan roti ketika mengajarkan pecahan. Selain itu siswa juga mengemukakan bahwa senang ketika diskusi kelompok karena dapat bertanya dengan teman 
yang lain dan dapat bekerjasama apabila ada siswa yang tidak bisa. Kemudian ketika presentasi juga bersama sama dan tidak hanya sendirian sehingga lebih berani menyampaikan hasil diskusinya.

Berdasarkan hasil wawancara dengan guru masih ada sebagian siswa yang minatnya kurang terhadap matematika hal ini dikarenakan faktor internal siswa misalnya menganggap matematika sulit dimengerti, ada siswa yang mengatakan ketika dibimbing guru bisa, namun ketika menghadapi permasalahan atau soal yang berbeda bingung dan tidak bisa mengerjakan karena kurang kegigihan dalam mengerjakan soal. Kemudian faktor eksternal yaitu dari orang tua karena orang tua sibuk bekerja jadi ketika dirumah tidak ada yang mendampingi belajar sehingga siswa kurang semangat ketika belajar matematika.

\section{SIMPULAN}

Pemberian diary siswa yang ditulis setelah kegiatan pembelajaran bermanfaat dalam mengetahui kesan dan perasaan siswa dalam kegiatan pembelajaran. Melalui diary siswa dapat disimpulkan bahwa minat belajar siswa tinggi hal ini diketahui dari siswa yang menulis "senang" kemudian pemberian stiker "ilovemath" pada diary siswa.

dengan siswa terdapat beberapa faktor pendukung minat belajar siswa diantaranya siswa senang ketika pembelajaran matematika karena menggunakan media pembelajaran yang bervariatif yaitu ada video dan ada media konkret seperti kubus satuan, uang mainan, dan roti ketika mengajarkan pecahan. Selain itu siswa juga mengemukakan bahwa senang ketika diskusi kelompok karena dapat bertanya dengan teman yang lain dan dapat bekerjasama apabila ada siswa yang tidak bisa. Kemudian ketika presentasi juga bersama sama dan tidak hanya sendirian sehingga lebih berani menyampaikan hasil diskusinya.

Berdasarkan hasil wawancara dengan guru masih ada sebagian siswa yang minatnya kurang terhadap matematika hal ini dikarenakan faktor internal siswa misalnya menganggap matematika sulit dimengerti, ada siswa yang mengatakan ketika dibimbing guru bisa, namun ketika menghadapi permasalahan atau soal yang berbeda bingung dan tidak bisa mengerjakan karena kurang kegigihan dalam mengerjakan soal. Kemudian faktor eksternal yaitu dari orang tua karena orang tua sibuk bekerja jadi ketika dirumah tidak ada yang mendampingi belajar sehingga siswa kurang semangat ketika belajar matematika.

Saran untuk guru setelah mengetahui minat belajar matematika maka dalam meningkatkan minat belajar siswa, guru harus merancang aktivitas belajar yang sesuai dengan kebutuhan dan kemampuan siswa, merancang pembelajaran yang bermakna bagi siswa dan berhubungan dengan dunia siswa, memberikan kesempatan kepada siswa untuk memperoleh pengalaman sukses, serta memberikan kesempatan siswa untuk belajar dan bekerja sama dengan siswa lain 


\section{DAFTAR PUSTAKA}

Aiken, L. R. 1999. Personality Assessment Methods and Practices $\left(3^{\text {rd }} \quad E d\right)$. Kirkland: Hogrefe \& Huber Publishers.

Ainley, M., Hidi, S., \& B, Dagmar. 2002. Interest, learning, and the psychological processes that mediate their relationship. Journal of Educational Psychology 2002, Vol. 94, No. 3, 545-561.

http://www.unco.edu/cebs/psych

ology/kevinpugh/motivation proje ct/resources/ainley etal02.pdf.

Diambil pada tanggal 01 Oktober 2019.

Arindiono, R. J., \& Ramadhani, N. 2013. perancangan media pembelajaran interaktif matematika untuk siswa kelas 5 SD. Jurnal Sains dan Seni ITS, 2(1), F28-F32.

Aryati, P. 2017. Pemanfaatan Captain's Diary untuk Menciptakan Lingkungan Belajar Yang Menyenangkan. UMS.

Asul, W, dkk. 2005. Mampu Berbahasa Indonesia SMP dan MTs Kelas VIII. Jakarta: Grasindo.

Depdiknas. 2006. Peraturan Menteri Pendidikan Nasional No. 22 tahun 2006 tentang standar isi mata pelajaran matematika.

Fricke, J. 2007. Generating Interest in Mathematics through Discussion in the Middle School Classroom. Action Research Poject Report. University of Nebraska-Lincoln. http://scimath.unl.edu/MIM/files/ research/FrickeJ.pdf. Diambil pada tanggal 01 Oktober 2019.

Haryati, N. 2015. Hubungan Minat Belajar Dengan Prestasi Belajar Matematika Siswa Kelas V Sd
Se-Gugus Wonokerto Turi Sleman Tahun Ajaran 2014/2015. Basic Education, 4(13).

Mayer, E. R. 2003). Memory and Information Processes. Handbook of psychology, vol. 7 Educational Psychology 2003. New York: John Wiley \& Sons. Inc.

Moleong, L.J. 2005. Metodologi Penelitian Kualitatif. Bandung: PT Remaja Rosdakarya.

Nitko, A. J., \& Brookhart, S. M. 2007. Educational assessment of students. Upper Saddle River, New Jersey: Pearson Education, Inc.

Nitko, A. J. \& Brookhart, S. M. 2011. Educational assessment of students, $6^{\text {th }}$ edition. USA: Pearson Education, Inc.

Oxford University Press. 2008. Oxford Learners Pocket Dictionary.

Savickas, L. M \& Spokane, R. A. (Eds.). 1999. Vocational interest: meaning, measurement, and counseling use. Palo Alto: Davies-Black Publishing

Siagian, R. E. F. 2015. Pengaruh minat dan kebiasaan belajar siswa terrhadap prestasi belajar matematika. Formatif: Jurnal IImiah Pendidikan MIPA, 2(2).

Smaldino,S. E., Lowther, L. D., \& Russel, J. D. 2008. Instructional technology and media for learning. ( $9^{\text {th }}$ ed). Upper Saddle River: Pearson Prentice Hall.

Sugiyono. 2013. Metode Penelitian Kuantitatif Kualitatif dan R\&D. Bandung: Alfabeta.

Trisniawati, T. Muanifah, M.T., Widodo, S.A \& Ardiyaningrum, M. 2019. Effect of Edmodo towards interests in mathematics learning. In Journal of Physics: 
Conference Series (Vol. 1188, p. 012103).

Woolfolk, A. 2007. Educational

Psychology. Boston: Pearson Education. 